\title{
Clinical evaluation, serological response and lesions generated by the A/Mexico/La Gloria-3/2009/H1N1 and A/swine/New Jersey/ 11/1976/H1N1 influenza viruses in colostrated and non-colostrated pigs
}

\author{
Mireya Juárez-Ramírez ${ }^{1}$ (1) Iván Sánchez-Betancourt ${ }^{2}$ - María Elena Trujillo-Ortega ${ }^{2}$. \\ Susana Mendoza-Elvira ${ }^{3} \cdot$ Rosalba Carreón-Nápoles $^{2} \cdot$ Benjamín Fuente-Martínez $^{4}$. \\ Francisco J. Trigo-Tavera ${ }^{1}$
}

Received: 5 January 2019/Accepted: 26 April 2019/Published online: 9 May 2019

(C) Indian Virological Society 2019

\begin{abstract}
Influenza A viruses cause respiratory disease in piglets, and maternal immunity plays an important role in protecting against Influenza virus infection. Nevertheless, in the presence of high levels of maternal antibodies against influenza, an adequate immune response is not developed. In this study, the effect of maternal antibodies against the swine influenza A/swine/New Jersey/11/1976/ H1N1 virus (swH1N1) on clinical presentation, serological response, and lesions produced in colostrated and noncolostrated pigs was evaluated in pigs infected with the human influenza A/Mexico/La Gloria-3/2009/ H1N1 $(\mathrm{pH} 1 \mathrm{~N} 1)$ and swH1N1 viruses. Our results indicated that
\end{abstract}

Electronic supplementary material The online version of this article (https://doi.org/10.1007/s13337-019-00531-8) contains supplementary material, which is available to authorized users.

Iván Sánchez-Betancourt

aisb_7@yahoo.com.mx

$\triangle$ Francisco J. Trigo-Tavera

trigo@unam.mx

1 Department of Pathology, School of Veterinary Medicine and Animal Science, National Autonomous University of Mexico, Mexico City, Mexico

2 Department of Swine Medicine and Management, School of Veterinary Medicine and Animal Science, National Autonomous University of Mexico, Mexico City, Mexico

3 Laboratory of Virology and Microbiology of Swine Respiratory Diseases. Multidisciplinary Research Unit. Cuautitlán Campus 1, National Autonomous University of Mexico, Mexico City, Mexico

4 Teaching, Research, and Extension Center in Avian Production (C.E.I.E.P.Av.), School of Veterinary Medicine and Animal Science, National Autonomous University of Mexico, Mexico City, Mexico between 2 and 4 days post-challenge, sneezing and mild nasal discharge were observed in all pigs. Body temperature in pigs from all treatment groups ranged between 39.2 and $39.3^{\circ} \mathrm{C}$. Pigs inoculated with the $\mathrm{pH} 1 \mathrm{~N} 1$ virus (421 g) exhibited a significantly lower daily weight gain than those inoculated with the swH1N1 virus $(524 \mathrm{~g})$. HI antibody titers against the $\mathrm{pH} 1 \mathrm{~N} 1$ virus were significantly different between colostrated (1.62) and non-colostrated $(0.43)$ pigs. Significant differences in antibody titers were detected between pigs inoculated with the pH1N1 (1.28) or the swH1N1 virus $(0.77) \quad(P<0.05)$. The highest percentage of pulmonary lesions was observed in noncolostrated/pH1N1 pigs $(11.88 \%)$ at 6 days post-challenge. Cross reactivity was observed between the pH1N1 and swH1N1 viruses, as the maternal antibodies against the swH1N1 virus successfully neutralized the pH1N1 virus infection.

Keywords Influenza virus · Pandemic virus · Swine virus · H1N1

\section{Introduction}

Influenza A viruses infect a wide variety of animal species, including pigs. The influenza subtypes that have been established in swine populations correspond to H1N1, $\mathrm{H} 1 \mathrm{~N} 2$, and H3N2. Virulent H1N1 subtypes of swine influenza generally cause a respiratory episode of acute course. During these infections, sneezing, coughing, dyspnea, nasal and ocular discharge, fever, and prostration are generally observed, followed by rapid recovery [1]. The H1N2 and H3N2 subtypes, in addition to causing respiratory problems, have been associated with abortions $[2,3]$. 
One of the prevention strategies used against Influenza virus is the vaccination of breeders, not only to protect the breeding herd, but also to provide passive or maternal immunity to the progeny through colostrum. Maternal immunity plays an important role in protecting against influenza virus infection in young pigs; however, antibody titers in newborn piglets are dependent on the antibody levels of the sow. Circulating levels of maternal antibodies in piglets may be detected between 4 and 14 weeks of age. Kitikoon et al. [4], observed that in the presence of high levels of maternal antibodies against influenza, an adequate immune response is not necessarily developed; therefore, young pigs may be highly susceptible to reinfection. On the other hand, when maternal antibody levels are low, immune response to the infective virus is weak or delayed. Currently, there are sufficient means to determine the genetic characteristics of viruses that circulate in pig populations; however, commercial vaccines usually only contain between one and three different isolates. Furthermore, these vaccines are not updated as in the case of vaccines intended for human use. Therefore, the level of cross-protection between genetically heterologous isolates of the same subtype is unpredictable [5].

In Kyriakis et al. [6] pandemic H1N1 human influenza A virus isolates were obtained from pigs in different countries, such as: Canada, Argentina, Australia, Singapore, Ireland, the United States, Japan, and Iceland. The clinical presentation, lesions, and intensity varied even within the same farm; this variation was attributed to age, handling, and interaction with other infectious agents [7-9]. Kyriakis et al. [6] observed a serological cross-reaction between the pandemic influenza H1N1 A virus and the European swine influenza virus; however, these authors considered that, although this cross-reactivity could confer a certain degree of protection, a test performed under controlled conditions would be necessary to confirm this hypothesis.

In the present study, we evaluated the effect of maternal antibodies against the swine influenza A/swine/New Jersey/11/1976/H1N1 virus on clinical presentation and serological response in colostrated and non-colostrated pigs, after infection with the human influenza $\mathrm{A} / \mathrm{Mexico} / \mathrm{La}$ Gloria-3/2009/ H1N1 (referred hereinafter as pH1N1) and swine influenza A/swine/New Jersey/11/1976/H1N1 (referred hereinafter as swH1N1) viruses.

\section{Materials and methods}

\section{Animal care}

Animal care, handling, and sampling protocols complied with the procedures approved by the Institutional
Committee for Care and Use of Experimental Animals (SICUAE) of the Graduate Degree Program in Production Sciences and Animal Health number DC-2010/2-3, UNAM.

A total of 36 crossbred pigs were used, of which 18 were colostrated [C] and 18 were non-colostrated [NC].

All colostrated pigs came from sows vaccinated with strain A/swine/New Jersey/11/1976/H1N1. The average weight of these animals was $8.13 \pm 0.39 \mathrm{~kg}$. All animals were housed in isolation units and kept at an environmental temperature ranging between 28 and $30{ }^{\circ} \mathrm{C}$ throughout the experiment. $\mathrm{C}$ pigs had an adaptation period of 2 weeks, during which they received food and water ad libitum. On the other hand, NC pigs were separated from the sow at the time of birth; they were dried off, and their umbilical cords were ligated, cut, and disinfected. Subsequently, they were fed with a milk substitute (Bayovac Lactomilk ${ }^{\circledR}$, Bayer Animal Health Laboratories), which was provided until 21 days of age. From the 7th day of age and until the end of the experiment, these pigs received commercial pelleted feed (NUPIG UNO Evolution ${ }^{\circledR}$, Nutec Group) and water ad libitum. To reduce the risk of bacterial infections, from 1 to 7 days of age, the experimental pigs received enrofloxacin (5\% injectable Baytril ${ }^{\circledR}$, Bayer Animal Health Laboratories) at a dosage of $2.5 \mathrm{mg} / \mathrm{kg}$ via intramuscular injection. Additionally, 5 days before virus inoculation, pigs were treated with intramuscular tylosin (Macrotyl ${ }^{\circledR}$, MAVER Laboratories) at a dosage of $20 \mathrm{mg} / \mathrm{kg}$.

\section{Experiment design}

Experimental pigs were allotted to a completely randomized $2 \times 2$ factorial design; where the first factor was colostrum (C and $\mathrm{NC}$ ) and the second factor was virus type $(\mathrm{pH} 1 \mathrm{~N} 1$ and swH1N1). Half of the pigs (18) were intranasally inoculated with the influenza A/Mexico/La Gloria3/2009/H1N1 (GenBank: CY077595) virus, and the other half (18) with the influenza A/swine/New Jersey/11/1976/ H1N1 (Gen-Bank: K00992) virus, using $5 \mathrm{~mL}$ of a solution containing a viral titer of 1:64 hemagglutinating units (UHA) as measured by hemagglutination (HA); $10^{6.9}$ RNA copies/ $\mu \mathrm{L}$ by real-time RT-PCR for the two viruses, with $1 \times 10^{3} \mathrm{DICC}_{50 \%}$ for the $\mathrm{pH} 1 \mathrm{~N} 1$ virus, and $1 \times 10^{1} \mathrm{DICC}_{50 \%}$ for the swH1N1 virus. Treatments were as described in Table 1.

Table 1 Experiment design

\begin{tabular}{lllll}
\hline Group & Colostrum & Challenge & Age (days) & N \\
\hline CpH1N129 & Yes & pH1N1 & 29 & 9 \\
NCpH1N129 & No & pH1N1 & 29 & 9 \\
CswH1N136 & Yes & swH1N1 & 36 & 9 \\
NCswH1N136 & No & swH1N1 & 36 & 9 \\
\hline
\end{tabular}




\section{Blood Samples and Assays}

Blood samples were collected via jugular venipuncture from all pigs prior to the start of the study, as well as from directly infected pigs on days $1,3,6,9,12$, and 14 postinoculation. Pigs were screened serologically for several common respiratory disease agents prior to the beginning of the study. Antibody titers to porcine Circovirus type 2 (INGEZIM CIRCO IgG $^{\circledR}$ Immunology and Applied Genetics SA), Porcine Reproductive and Respiratory Syndrome (HerdChek * PRRS $2 \mathrm{XR}^{\circledR}$, IDEXX Laboratories, Inc.), and Mycoplasma hyopneumoniae (HerdChek*M hyo ${ }^{\circledR}$, IDEXX Laboratories, Inc.) were measured using commercial ELISA kits based on the manufacturer's specifications. Hemagglutination inhibition assay (HI) against blue eye Paramyxovirus was performed according to the method described by Ramírez et al. [10]. The influenza $\mathrm{HI}$ test was performed according to the procedure described by the World Organization for Animal Health (OIE) for influenza A viruses pH1N1, swH1N1, and H3N2.

\section{Clinical measurements and macroscopic lesions}

The pigs were monitored daily for signs of illness, such as: sneezing, coughing, dyspnea, nasal discharge, and ocular discharge. Rectal temperature and average daily gain (ADG) were measured.

Euthanasia and necropsy were performed in three pigs per treatment group on days 2,6 , and 14 post-inoculation. The decision to euthanize on these specific days was made considering the following factors: viral incubation period ( 2 days), persistence of the virus in the respiratory tract ( 2 weeks), and time needed to generate an immune response (7-10 days). Additionally, these days aligned with previous published works which utilized similar ranges. Euthanasia was achieved by inducing pigs to a deep anesthetic plane, with subsequent exsanguination. The pigs received a dose of $2.2 \mathrm{mg} / \mathrm{kg}$ of xylazine $\left(\mathrm{PROCIN}^{\circledR} \mathrm{PiSA}\right.$ Agropecuaria) and $4.4 \mathrm{mg} / \mathrm{kg}$ of Tiletamine-Zolacepam (Zoletil ${ }^{\circledR} 50$ Virbac Animal Health) intramuscularly. This mixture of tranquilizers and anesthetics facilitated sedation and immobilization prior to exsanguination [11]. Each pig was then submitted to necropsy with special emphasis on the respiratory tract, where the percentage of pulmonary lesions was determined according to the methodology described by Sorensen et al. [12].

\section{Statistical analyses}

While results for clinical signs were presented as proportions, body temperature and percent of pulmonary lesions were transformed using the Box-Cox technique: $\lambda=\frac{(\text { Percent of pulmonary lesions }+1)^{-0.2}-1}{-0.072}$. Antibody titers were transformed to $\log 10$. Transformed data and daily weight gain were analyzed as a completely randomized design with a multivariate factorial arrangement $2 \times 2 \times 14$ [13]; where the first factor was colostrum (C and $\mathrm{NC}$ ), the second factor was virus type (pH1N1 and swH1N1), and the third factor was the number of days post-inoculation. For data analysis, the JMP ${ }^{\circledR} 8$ statistical package was used.

\section{Results \& Discussion}

\section{Clinical measurements}

Upon clinical evaluation prior to inoculation (Table 2), no sneezing, coughing, dyspnea, nasal discharge, or ocular discharge were detected in any of the pigs. Between days 2 and 4 post-inoculation, sneezing and mild nasal discharge were detected in all treatment groups. Body temperature in the four treatment groups ranged from 39.2 to $39.3{ }^{\circ} \mathrm{C}$ (Table 3). No significant statistical evidence was found that colostrum, virus strain, or their interactions had any effect on body temperature in any of the treatment groups $(P>0.05)$. Of note, a typical clinical presentation caused by Influenzavirus, as described by Brookes et al. [14] and Lange et al. [15], in non-colostrated pigs inoculated with Influenzavirus A H1N1 strains A/ California/ 07/2009 (H1N1) and A/Regensburg/D6/ 2009 (H1N1), respectively, included ocular and nasal discharge, coughing, salivation, increase in respiratory rate, lethargy, inappetence, diarrhea, palpebral edema, and fever. In our study, only sporadic sneezing and mild nasal discharge were observed, which were detected for a period of $3-8$ days, depending on the virus with which the pigs were inoculated, as well as the presence or absence of colostrum. Additionally, there was not enough evidence to state that inoculation with influenza viruses pH1N1 and swH1N1 had any effect on body temperature, as all results obtained were within the normal range $\left(39.3^{\circ} \mathrm{C}\right.$ a $\left.39.6^{\circ} \mathrm{C}\right)$ for weaned pigs between 9 and $18 \mathrm{~kg}$ (supplementary Fig. a).

Lack of a clinical disease pattern typical of influenza is not unprecedented. Busquets et al. [16], inoculated noncolostrated pigs with swine influenza A virus H1N1 strain A/swine/Spain/53207/2004/H1N1, as well as with influenza A virus H1N1 strain A/Catalonia /63/2009 / H1N1, without observing any relevant respiratory or systemic signs. Futhermore, body temperature throughout the evaluation remained below $40^{\circ} \mathrm{C}$. Vincent et al. [17], evaluated 7 swine influenza virus subtype H1N1 isolates obtained in the United States and observed that clinical signs such as cough and anorexia were almost imperceptible, and that body temperature was $\geq 40^{\circ} \mathrm{C}$ in only 2 of the 7 isolations. 
Table 2 Results of the clinical evaluation performed on colostrated and non-colostrated pigs inoculated with influenza A viruses pH1N1 and swH1N1

\begin{tabular}{|c|c|c|c|c|c|c|c|c|}
\hline \multirow[t]{3}{*}{ DPI } & \multicolumn{4}{|c|}{ Colostrated } & \multicolumn{4}{|c|}{ Non colostrated } \\
\hline & \multicolumn{2}{|c|}{ pH1N1(C29) } & \multicolumn{2}{|c|}{ swH1N1(C36) } & \multicolumn{2}{|c|}{ pH1N1(N29) } & \multicolumn{2}{|c|}{ swH1N1(N36) } \\
\hline & Sneezing & Nasal discharge & Sneezing & Nasal discharge & Sneezing & Nasal discharge & Sneezing & Nasal discharge \\
\hline 0 & $0 / 9$ & $0 / 9$ & $0 / 9$ & $0 / 9$ & $0 / 9$ & $0 / 9$ & $0 / 9$ & $0 / 9$ \\
\hline 1 & $0 / 9$ & $0 / 9$ & $0 / 9$ & $0 / 9$ & $0 / 9$ & $0 / 9$ & $0 / 9$ & $0 / 9$ \\
\hline $2^{*}$ & $0 / 9$ & $0 / 9$ & $0 / 9$ & $0 / 9$ & $0 / 9$ & $0 / 9$ & $2 / 9$ & $2 / 9$ \\
\hline 3 & $3 / 6$ & $3 / 6$ & $0 / 6$ & $0 / 6$ & $0 / 6$ & $0 / 6$ & $2 / 6$ & $2 / 6$ \\
\hline 4 & $3 / 6$ & $3 / 6$ & $1 / 6$ & $1 / 6$ & $6 / 6$ & $6 / 6$ & $2 / 6$ & $2 / 6$ \\
\hline 5 & $3 / 6$ & $3 / 6$ & $1 / 6$ & $1 / 6$ & $6 / 6$ & $6 / 6$ & $0 / 6$ & $0 / 6$ \\
\hline $6^{*}$ & $3 / 6$ & $3 / 6$ & $1 / 6$ & $1 / 6$ & $6 / 6$ & $6 / 6$ & $0 / 6$ & $0 / 6$ \\
\hline 7 & $1 / 3$ & $1 / 3$ & $1 / 3$ & $1 / 3$ & $3 / 3$ & $3 / 3$ & $0 / 3$ & $0 / 3$ \\
\hline 8 & $2 / 3$ & $2 / 3$ & $0 / 3$ & $0 / 3$ & $2 / 3$ & $2 / 3$ & $0 / 3$ & $0 / 3$ \\
\hline 9 & $2 / 3$ & $2 / 3$ & $0 / 3$ & $0 / 3$ & $1 / 3$ & $1 / 3$ & $0 / 3$ & $0 / 3$ \\
\hline 10 & $1 / 3$ & $1 / 3$ & $0 / 3$ & $0 / 3$ & $0 / 3$ & $0 / 3$ & $0 / 3$ & $0 / 3$ \\
\hline 11 & $0 / 3$ & $0 / 3$ & $0 / 3$ & $0 / 3$ & $0 / 3$ & $0 / 3$ & $0 / 3$ & $0 / 3$ \\
\hline 12 & $0 / 3$ & $0 / 3$ & $0 / 3$ & $0 / 3$ & $0 / 3$ & $0 / 3$ & $0 / 3$ & $0 / 3$ \\
\hline 13 & $0 / 3$ & $0 / 3$ & $0 / 3$ & $0 / 3$ & $0 / 3$ & $0 / 3$ & $0 / 3$ & $0 / 3$ \\
\hline $14^{*}$ & $0 / 3$ & $0 / 3$ & $0 / 3$ & $0 / 3$ & $0 / 3$ & $0 / 3$ & $0 / 3$ & $0 / 3$ \\
\hline
\end{tabular}

DPI days post-infection, $p H 1 N 1$ human influenza virus A/México/La Gloria-3/2009/H1N1, swH1N1 swine influenza virus A/swine/New Jersey/ 11/1976/H1N1

*Euthanasia and necropsy were performed in three pigs per treatment group on days 2, 6, and 14 post-inoculation

Table 3 Body temperature, average daily gain (ADG), and pulmonary lesions in colostrated and non- colostrated pigs inoculated with influenza A viruses $\mathrm{pH} 1 \mathrm{~N} 1$ and swH1N1

\begin{tabular}{llll}
\hline & Body temperature $\left({ }^{\circ} \mathrm{C}\right)$ & Daily weight gain $(\mathrm{g})$ & Pulmonary lesions $(\%)$ \\
\hline Colostrum & & & \\
Yes & $39.3^{\mathrm{a}}$ & $478^{\mathrm{a}}$ & $0.86(1.14)^{\mathrm{b}}$ \\
No & $39.2^{\mathrm{a}}$ & $468^{\mathrm{a}}$ & $6.05(2.74)^{\mathrm{a}}$ \\
SEM & 0.02 & 18 & 0.23 \\
Virus & & & \\
pH1N1 & $39.2^{\mathrm{a}}$ & $421^{\mathrm{b}}$ & $6.47(3.23)^{\mathrm{a}}$ \\
swH1N1 & $39.3^{\mathrm{a}}$ & $524^{\mathrm{a}}$ & $0.44(0.66)^{\mathrm{b}}$ \\
SEM & 0.02 & 18 & 0.23 \\
Probability & & & $*$ \\
Colostrum & $\mathrm{NS}$ & $\mathrm{NS}$ & $*$ \\
Virus & NS & $*$ & $*$ \\
DPI & NS & NS & $*$ \\
Colostrum X virus & NS & $*$ & NS \\
Colostrum X DPI & NS & NS & $*$ \\
Virus X DPI & NS & NS & NS \\
Colostrum X virus X DPI & NS & NS & \\
\hline
\end{tabular}

Values in parentheses are transformed by the Box-Cox technique Different superscripts $(\mathrm{a}, \mathrm{b})$ indicate significant difference $(P<0.05)$

$S E M$ standard error of the mean, $N S$ not significant $* P<0.05$ 
These variations in the presentation and intensity of clinical signs caused by the influenza virus under experimental conditions depend on a variety of factors, such as: route of inoculation, infecting dose, type of strain, age of pigs at the time of inoculation, and pigs' immunological status. It is well-known that intratracheal inoculation with high doses of virus $\geq 10^{7.5} \mathrm{DIEP}_{50 \%}$ easily produces typical clinical signs and lesions of influenza, and that less invasive methods such as intranasal inoculation tend to cause only mild infections, such as the one observed in the present study, or completely subclinical infections, as observed by Busquets et al., [16]; these types of mild infections may be seen frequently in the field, and often go unnoticed.

In terms of field infections with pandemic influenza $\mathrm{A}$ H1N1 virus, descriptive case reports in swine in Canada (Alberta and Manitoba) and Argentina (Buenos Aires), highlighted ocular and nasal discharge, sneezing, coughing, abdominal breathing, depression, decreased feed intake, fever, dehydration, and mortality reaching 1 to $2 \%$ in some areas, despite previous vaccination with Maxivac ${ }^{\circledR} \mathrm{H} 1 \mathrm{~N} 1$ (Schering-Plough Animal Health, Kirkland, Quebec). This severe presentation was attributed to the interaction of Influenzavirus with Porcine Reproductive and Respiratory Syndrome, porcine Circovirus type 2, Mycoplasma hyopneumoniae, and Actinobacillus pleuropneumoniae, which were present in some areas of the affected farms [7-9].

No significant differences were detected in ADG between $\mathrm{C}$ pigs and $\mathrm{NC}$ pigs; however, pigs inoculated with the pH1N1 virus had a significantly lower ADG than those inoculated with the swH1N1 virus. When evaluating the interaction between colostrum and virus, the CpH1N129 treatment showed a significantly lower ADG than the CswH1N136 group (Table 3). Infection with both viral strains was seen to affect ADG; however, ADG was significantly affected by the $\mathrm{pH} 1 \mathrm{~N} 1$ virus infection even in the presence of maternal antibodies. Weight loss is a welldescribed effect in influenza infections with different strains and in different animal models, and has been associated with the production of IL1, IL6, TNF- $\alpha$, and acute phase proteins (C-reactive protein and haptoglobin) $[14,18]$.

\section{Antibody titers}

Serum samples from the four treatment groups before inoculation showed negative antibody titers to Blue Eye Paramyxovirus $(36 / 36 ; \leq 1: 16)$ and Influenza subtype $\mathrm{H} 3 \mathrm{~N} 2(36 / 36 ; \leq 1: 80)$ as measured by $\mathrm{HI}$, as well as to Mycoplasma hyopneumoniae (36/36; S/P ratio $\leq 0.30$ ), porcine Circovirus type $2(36 / 36$; OD $\leq 0.40)$, and Porcine Reproductive and Respiratory Syndrome (36/36;S/P ratio $\leq 0.40$ ), as measured by ELISA. In the case of HI for the $\mathrm{pH} 1 \mathrm{~N} 1$ and swH1N1 viruses, all non-colostrated pigs were negative, while in the colostrated pigs, $15 / 18$ sera were positive for the $\mathrm{pH} 1 \mathrm{~N} 1$ virus, and 18/18 sera were positive for the swH1N1 virus (supplementary Tables a, b).

$\mathrm{HI}$ titers against the $\mathrm{pH} 1 \mathrm{~N} 1$ virus were significantly different between the colostrated and non-colostrated pigs. Furthermore, a significant difference was detected between $\mathrm{HI}$ titers of pigs inoculated with the $\mathrm{pH} 1 \mathrm{~N} 1$ virus and those inoculated with the swH1N1 virus (Table 4). Antibody titers of the NCpH1N1 pigs (0.86) were significantly higher than titers in the NCswH1N1 pigs $(0.00)(P<0.05)$. A significant difference was detected between antibody titers of the non-colostrated and colostrated pigs from days 0 to 9 post-inoculation, as no antibodies were detected from days 0 to 6 post-inoculation in non-colostrated pigs, whereas antibody titers were higher than 1.5 in colostrated pigs during the same timeframe. At day 9 post-inoculation, antibody titers in NC pigs (0.85) were lower than in $\mathrm{C}$ pigs (1.48) $(P<0.05)$. At days 12 and 14 post-inoculation, antibody titers were not significantly different in $\mathrm{NC}$ and $\mathrm{C}$ pigs. Both viral strains had a similar effect on antibody titers from days 0 to 6 post-infection; however, from days 9 to 14 post-infection, antibody titers of pigs inoculated with the $\mathrm{pH} 1 \mathrm{~N} 1$ virus increased, whereas titers remained low in pigs inoculated with the swH1N1 virus.

A significant difference was observed in antibody titers to the swH1N1 virus in NC and C pigs. Antibody titers of

Table 4 Antibody titers expressed in $\log 10$ obtained by the hemagglutination inhibition test in colostrated and non- colostrated pigs inoculated with influenza A viruses $\mathrm{pH} 1 \mathrm{~N} 1$ and swH1N1

\begin{tabular}{lll}
\hline & \multicolumn{2}{l}{ Hemagglutination inhibition } \\
\cline { 2 - 3 } & pH1N1 & swH1N1 \\
\hline Colostrum & $1.62^{\mathrm{a}}$ & $2.13^{\mathrm{a}}$ \\
Yes & $0.43^{\mathrm{b}}$ & $1.98^{\mathrm{b}}$ \\
No & 0.04 & 0.03 \\
SEM & & \\
Virus & $1.28^{\mathrm{a}}$ & $2.13^{\mathrm{a}}$ \\
pH1N1 & $0.77^{\mathrm{b}}$ & $1.99^{\mathrm{b}}$ \\
swH1N1 & 0.04 & 0.03 \\
SEM & & \\
Probability & $*$ & $*$ \\
Colostrum & $*$ & $*$ \\
Virus & $\mathrm{NS}$ & $\mathrm{NS}$ \\
DPI & $*$ & $\mathrm{NS}$ \\
Colostrum X virus & $*$ & $*$ \\
Colostrum X DPI & $* \mathrm{NS}$ & $\mathrm{NS}$ \\
Virus X DPI & & $\mathrm{NS}$ \\
Colostrum X virus X DPI & &
\end{tabular}

$\overline{\text { Different superscripts }(\mathrm{a}, \mathrm{b}) \text { indicate significant differences }(P<0.05)}$ $S E M$ standard error of the mean, NS not significant

$* P<0.05$ 
pigs inoculated with the $\mathrm{pH} 1 \mathrm{~N} 1$ virus and those inoculated with the swH1N1 virus were significantly different. No significant relationship between colostrum and the type of virus was found on antibody titers (Table 4). Titers in noncolostrated pigs (1.82 and 1.90) were significantly lower than those from colostrated pigs $(2.20$ and 2.15$)(P<0.05)$ at days 0 and 1 post-inoculation. From day 3 to 14 postinoculation, antibody titers in $\mathrm{NC}$ and $\mathrm{C}$ pigs were not different. No significant interaction between virus type and post-inoculation days was found $(P>0.05)$. Significant differences were detected in antibody titers associated with the type of strain used in the HI test and the virus strain used for the challenge, as well as due to the absence or presence of maternal antibodies. When the swH1N1 virus was used as an antigen in the $\mathrm{HI}$ test, antibody titers were higher than those observed when the pH1N1 virus was used. These discrepancies between the reactivity of one virus versus another have already been documented, as has their impact on diagnostic protocols [19, 20].

Upon evaluation of antibody titers, it was clear that pigs infected with the pH1N1 virus developed higher antibody titers regardless of the antigen used in the HI test. This was associated with the degree of immune stimulation, probably due to a higher capacity for virus replication and virulence of the pH1N1 virus. These observations were confirmed when a higher percentage of pulmonary lesions was recorded. Regarding the role of antibodies, in the case of non-colostrated/pH1N1 pigs, antibodies were detected in the serum against the pH1N1 virus from day 9 post-inoculation, which aligns with that reported by Brookes et al. [14], Lange et al. [15], and Busquets et al. [16], in which antibodies were detected after day 7 post-inoculation. A cross-serological reaction was observed in colostrated pigs, which was later substantiated by the lower degree of pulmonary lesions in animals in these treatment groups.
Serological cross-reactions between strains of the H1N1 subtype in pigs have indeed been previously described [20]. Kyriakis et al. [6], observed a cross-serological reaction between the pandemic influenza $\mathrm{A} H 1 \mathrm{~N} 1$ virus and the swine influenza virus in experimentally inoculated, vaccinated, and hyperimmunized pigs with classic American and European strains of swine influenza virus subtypes H1N1 and H1N2. Perera et al. [21] described cross-reactivity to the main swine subtype $\mathrm{H} 1$ viruses in humans with antibodies to the pandemic influenza A H1N1 virus.

\section{Macroscopic lesions}

During necropsy, the only organ in which evident macroscopic lesions were observed was the lung, which is consistent with previous reports (Vincent et al. [17], Brookes et al. [14], Lange et al. [15], and Busquets et al. [16]). Affected pulmonary tissue was red in color, firm in texture, and clearly delimited by normal pulmonary tissue. The affected areas were predominantly the cranial and middle lobes (Fig. 1). In some cases, atelectasis and emphysema were observed in the caudal lobes. The percentage of pulmonary lesions seen was between $0.5 \%$ and $29 \%$; this percentage (Table 3) was higher in non-colostrated pigs compared to colostrated pigs. On the other hand, pigs inoculated with the $\mathrm{pH} 1 \mathrm{~N} 1$ virus had a higher percentage of lesions than those inoculated with the swH1N1 virus. The percentage of pulmonary lesions between colostrated/ pH1N1 [1.05\% (1.40)] and colostrated/swH1N1 [0.66\% $(0.88)]$ pigs was not significantly different $(P>0.05)$; however, the percentage of pulmonary lesions in noncolostrated/pH1N1 pigs [11.88\% (5.05)] was significantly higher than in non-colostrated/swH1N1 pigs $[0.22 \%$ $(0.44)](P<0.05)$. Pigs inoculated with the $\mathrm{pH} 1 \mathrm{~N} 1$ virus had a higher percentage of lesions at day 6 post-inoculation
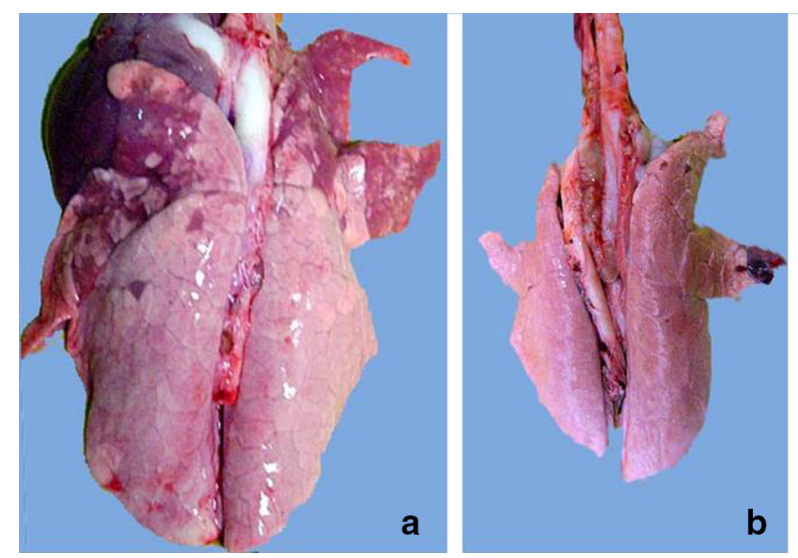

Fig. 1 Macroscopic lesions observed in lungs of colostrated and noncolostrated pigs inoculated with $\mathrm{pH} 1 \mathrm{~N} 1$ and swH1N1 viruses at day 6 post-inoculation. In lungs identified as (a) NCpH1N129, b CpH1N129, and c CswH1N136, small to moderate, red, irregular

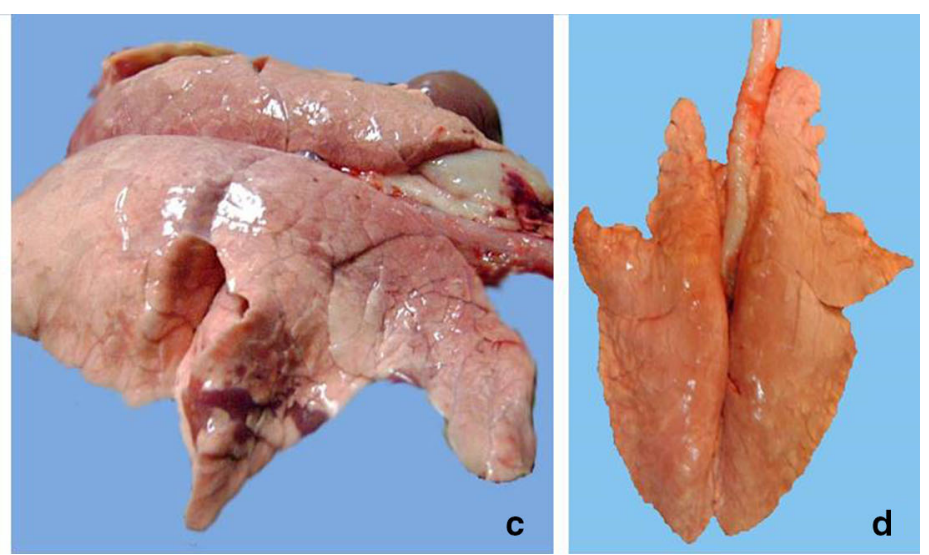

areas of consolidation are observed, delimited by normal lung tissue in the cranial and middle lobes. d NCswH1N136 does not exhibit evident macroscopic changes 
$[12.1 \%(4.64)]$ than at day $2[3.5 \%(2.57)]$ and day 14 $[3.83 \%(2.48)]$ post-inoculation $(P<0.05)$. The percentage of pulmonary lesions in pigs inoculated with the swH1N1 virus was not significantly different throughout the post-inoculation period $(P>0.05)$. There was no significant interaction between the effect of colostrum and days post-inoculation $(P>0.05)$. The highest percentage of pulmonary lesions was observed in non-colostrated/ pH1N1 pigs at day 6 post-inoculation, which may be due to both a lack of immunity against the $\mathrm{pH} 1 \mathrm{~N} 1$ virus and its high infective capacity.

The virulence of the $\mathrm{pH} 1 \mathrm{~N} 1$ virus has been previously established in different animal models and has been shown to be superior to that of porcine or seasonal human strains [14-16, 22-24]. This characteristic was also corroborated in our research, as pigs inoculated with the swH1N1 virus had a lower percentage of pulmonary lesions than those inoculated with the $\mathrm{pH} 1 \mathrm{~N} 1$ virus. Discrepancies in the incidence of lesions between swine influenza virus strains of the same subtype have been reported elsewhere. In a study conducted by Vincent et al. [17], seven isolates of swine influenza virus subtype H1N1 were evaluated in colostrum-deprived pigs from the United States. In that study, the percentage of pulmonary lesions ranged between 8 and $30 \%$. Therefore, disparities in the infective capacity of the virus and its pathogenicity amongst isolates may be associated with the ability of each strain to inhibit or activate the host defense mechanisms.

Variations in the number of affected animals and the duration of clinical signs suggest that, under the conditions of the present study, the clinical behavior of the pH1N1 virus differs from that of the swH1N1 virus. Inoculation with $\mathrm{pH} 1 \mathrm{~N} 1$ and swH1N1 viruses had no effect on body temperature, which remained in the normal range for weaned pigs between 9 and $18 \mathrm{~kg}\left(39.3-39.6^{\circ} \mathrm{C}\right)$. However, infection with the $\mathrm{pH} 1 \mathrm{~N} 1$ virus had a negative effected on weight gain, as pigs inoculated with this virus (421 g), had a lower daily weight gain than those pigs inoculated with swH1N1 (542 g). Additionally, inoculation with $\mathrm{pH} 1 \mathrm{~N} 1$ resulted in a greater incidence of macroscopic pulmonary lesions in non-colostrated pigs.

In terms of antibody production, discrepancies were also noted. Antibody titers obtained via hemagglutination inhibition were higher in pigs inoculated with pH1N1 than in pigs inoculated with swH1N1. Furthermore, a serological cross-reaction between the $\mathrm{pH} 1 \mathrm{~N} 1$ and swH1N1 viruses was observed in the HI assay. Maternal antibodies to porcine influenza subtype H1N1 successfully neutralized both pH1N1 and swH1N1, which was later confirmed by a lower incidence of pulmonary lesions in colostrated pigs.

On the other hand, the presence of colostral antibodies undoubtedly plays an important role in the prevention of early exposure to Influenzavirus and these is fundamental in the development of adequate vaccination protocols, which can help avoid subclinical or minor infections that may go unnoticed, favoring the adaptation of new emerging Influenzavirus strains. Therefore, updating laboratory strains used in diagnosis and in vaccine elaboration is crucial to instituting satisfactory prevention and control programs for this disease.

Acknowledgments The authors express their gratitude to the staff of the Pathology Department and of the Department of Swine Medicine and Management, of the School of Veterinary Medicine and Animal Science, National Autonomous University of Mexico.

\section{Compliance with ethical standards}

Conflict of interest The authors declare that they have no conflict of interest regarding the publication of this study.

\section{References}

1. Olsen CW, Brown IH, Easterday BC, Reeth KV. Swine Influenza. In: Straw BE, Zimmerman JJ, D'Allaire S, Taylor DJ, editors. Diseases of swine. 9th ed. Ames, Iowa: Blackwell Publishing. 2006. pp 469-482.

2. Karasin AI, Schutten MM, Cooper LA, Smith CB, Subbarao K, Anderson GA, Carman S, Olsen CW. Genetic characterization of H3N2 influenza viruses isolated from pigs in North America, 1977-1999: evidence for wholly human and reassortant virus genotypes. Virus Res. 2000;68(1):71-85.

3. Zhou NN, Senne DA, Landgraf JS, Swenson SL, Erickson G, Rossow K, Liu L, Yoon KJ, Krauss S, Webster RG. Emergence of H3N2 reassortant influenza A viruses in North American pigs. Vet Microbiol. 2000;74(1-2):47-58.

4. Kitikoon P, Nilubol D, Erickson BJ, Janke BH, Hoover TC, Sornsen SA, Thacker EL. The immune response and maternal antibody interference toa heterologous H1N1 swine influenza virus infection following vaccination. Vet ImmunolImmunopathol. 2006;112(3-4):117-28.

5. Grebe KM, Yewdell JW, Bennink JR. Heterosubtypic immunity to influenza A virus: where do we stand? Microbes Infect. 2008;10(9):1024-9.

6. Kyriakis CS, Olsen CW, Carman S, Brown IH, Brookes SM, Doorsselaere JV, et al. Serologic cross-reactivity with pandemic (H1N1) 2009 virus in pigs, Europe. Emerg Infect Dis. 2010;16:96-9.

7. Howden KJ, Brockhoff EJ, Caya FD, McLeod LJ, Lavoie M, Ing $\mathrm{JD}$, et al. An investigation into human pandemic influenza virus (H1N1) 2009 on an Alberta swine farm. Can Vet J. 2009;50:1153-61.

8. Pasma T, Joseph T. Pandemic (H1N1) 2009 infection in swine herds, Manitoba, Canada. Emerg Infect Dis. 2010;16:706-8.

9. Pereda A, Cappuccio J, Quiroga MA, Baumeister E, Insarralde L, Ibar M, et al. Pandemic (H1N1) 2009 Outbreak on pig farm, Argentina. Emerg Infect Dis. 2010;16:304-7.

10. Ramírez MH, Carreón NR, Mercado GC, Rodríguez TJ. Hemoaglutinación e inhibición de la hemoaglutinación del paramixovirus porcino a través de la modificación de algunas variables que participan en la prueba. Vet Mex. 1996;27(3):257-9.

11. Bollen AJP, Hansen KA, Rasmussen JH. The laboratory swine. Florida: CRC Press LLC; 2000. 
12. Sorensen V, Jorsal SE, Mousing J. Diseases of the respiratory system. In: Straw BE, Zimmerman JJ, D'Allaire S, Taylor DJ, editors. Diseases of swine. 9th ed. Ames, Iowa: Blackwell Publishing; 2006. pp. 149-178.

13. Hair JF, Anderson RE, Tatham RL, Black WC. Multivariate data analysis. 4th ed. New Jersey: Prentice Hall; 1995.

14. Brookes SM, Núñez A, Choudhury B, Matrosovich M, Essen SC, et al. Replication, Pathogenesis an Transmission of Pandemic (H1N1) 2009 Virus in Non-Immune Pigs. PLoS ONE. 2009;5(2):e9068. https://doi.org/10.1371/journal.pone.0009068.

15. Lange E, Kalthoff D, Blohm U, Teifke JP, Breithaupt A, Maresch $\mathrm{C}$, et al. Pathogenesis and transmission of the novel swine-origin influenza virus $\mathrm{A} / \mathrm{H} 1 \mathrm{~N} 1$ after experimental infection of pigs. J Gen Virol. 2009;90(Pt9):2119-23.

16. Busquets N, Segalés J, Córdoba L, Mussá T, Crisci E, MartinValls GE, et al. Experimental infection with H1N1 European swine influenza virus protects pigs from an infection with the 2009 pandemic H1N1 human influenza virus. Vet Res. 2010;41:74.

17. Vincent AL, Larger KM, Ma W, Lekcharoensuk P, Gramer MR, Loiacono C, et al. Evaluation of hemagglutinin subtype 1 swine influenza viruses from the USA. Vet Microbiol. 2006;118:212-22.

18. Van Reeth K, Nauwynck H. Proinflammatory cytokines and viral respiratory disease in pigs. Vet Res. 2000;31(2):187-213.
19. Long BC, Goldberg TL, Swenson SL, Erickson G, Scherba G. Adaptation and limitations of established hemagglutination inhibition assays for the detection of porcine anti-swine influenza virus H1N2 antibodies. J Vet Diagn Invest. 2004;16(4):264-70.

20. Leuwerke B, Kitikoon P, Evans R, Thacker E. Comparison of three serological assays to determine the cross-reactivity of antibodies from eight genetically diverse USA swine influenza virus. J Vet Diagn Invest. 2008;20:426-32.

21. Perera RA, Riley S, Ma SK, Zhu HC, Guan Y, Peiris JS. Seroconversion to pandemic (H1N1) 2009 virus and cross-reactive immunity to other swine influenza viruses. Emerg Infect Dis. 2011;17:1897-9.

22. Itoh Y, Shinya K, Kiso M, Watanabe T, Sakoda Y, Hatta M, et al. In vitro and in vivo characterization of new swine-origin H1N1 influenza viruses. Nature. 2009;460:1021-5.

23. Munster VJ, de Wit E, van den Brand JM, Herfst S, Schrauwen EJ, Bestebroer TM, et al. Pathogenesis and transmission of swineorigin 2009 A (H1N1) influenza virus in ferrets. Science. 2009;325:481-3.

24. Rowe T, León AJ, Crevar CJ, Carter DM, Xu L, Ran L, et al. Modeling host responses in ferrets during A/California/07/2009 influenza infection. Virology. 2010;401:257-65.

Publisher's Note Springer Nature remains neutral with regard to jurisdictional claims in published maps and institutional affiliations. 